\title{
Argentina (1976-1983): impacto y afrontamiento psicosocial*
}

\section{Argentina (1976-1983): Psychosocial Consequences and Coping}

Enviado: 26 de mayo de 2013 | Revisado: 16 de octubre de 2014 | Aceptado: 15 de abril de 2015

\author{
Maitane ARnoso Martinez*** \\ AINARA ARNOSO MARTINEZ *** \\ Universidad del País Vasco, España.
}

Pau PÉrez SAles *****

Grupo de Acción Comunitaria, España.

doi:10.11144/Javeriana.upsy14-3.aiap

Para citar este artículo: Arnoso, M., Arnoso, A., \& Pérez, P. (2015). Argentina (1976-1983): Impacto y afrontamiento psicosocial. Universitas Psychologica, 14(3), 833-842. http://dx.doi.org/10.11144/Javeriana.upsy14-3.aiap

" Agradecimientos a las organizaciones de familiares y ex detenidos/as políticos/as de Jujuy. A la Dirección de Política Científica y Universidades del Gobierno Vasco por la financiación concedida a través de una beca DKR.

*** Dra. Ciencia Política. Profesora en el Departamento de Psicología Social y Metodología de CC.CC. Universidad del País Vasco. Correo electrónico: maitane_arnoso@yahoo.es

**** Dra. Psicología Social. Profesora en el Departamento de Psicología Social y Metodología de CC.CC. Universidad del País Vasco. Correo electrónico: ainara.arnoso@ehu.es

***** Dr. Psiquiatría. Miembro del Grupo de Acción Comunitaria. Centro de Recursos en Salud Mental y Derechos Humanos. Correo electrónico: pauperez@arrakis.es

\section{RES UMEN}

El presente estudio explora el impacto que tuvo la violencia represiva de la última dictadura militar argentina en una muestra de familiares de personas detenidas desaparecidas $(\mathrm{n}=30)$ y de personas que sobrevivieron a las cárceles de la dictadura $(n=22)$. De los resultados se extrae que un tipo de afrontamiento activo de la experiencia y un apoyo social positivo, se relaciona con la posibilidad de dar sentido a lo ocurrido y la generación de una identidad en el sobreviviente. A la inversa, las formas de afrontamiento marcadas por la evitación se relacionan con más sintomatología de estrés postraumático, mayor alteración en el proceso de duelo y mayor impacto negativo en las creencias básicas.

Palabras clave

violencia colectiva; sobrevivientes; impacto psicosocial; afrontamiento; crecimiento

\section{A B S T R A C T}

This study explores the impact of repressive violence during the last Argentinean military dictatorship's on a sample of relatives of people detained-disappeared for political reasons $(n=30)$ and people who survived imprisionment and torture $(n=22)$. Facing of the experience from a political point of view, remaining socially active and positive social support are string elements in providing sense to the experience and generating a positive identity as a survivor. Viceversa, hidding and avoidance are related to post-traumatic symptoms, difficulties in the mourning process and a greater negative impact on basic beliefs.

Keywords

colective violence; survivors; psychosocial consequences; coping; post-traumatic growth 


\section{Introducción}

Diversas investigaciones en distintos contextos han mostrado que la violencia política tiene repercusiones psicosociales sobre las personas y colectividades que la enfrentan. Uno de los cuadros clínicos más utilizados ha sido el Síndrome de Estrés Postraumático, aunque a menudo la sintomatología responde a reacciones iniciales de alcance limitado y con tendencia a volver rápidamente a los niveles normales (Summerfield, 1999). Kordon, Edelman, Lagos y Kersner (1995) plantearon el concepto de duelo en contextos de violencia política donde la pérdida de muchas personas y la ausencia de rituales de duelo o luto, parecen ser factores de riesgo que inciden en su normal desarrollo.

En general, las personas que han soportado acontecimientos traumáticos tienen necesidad de dar sentido a la experiencia del terror y la muerte violenta e irrazonada (Cabrera, 2006). La búsqueda del sentido genera discusiones colectivas acerca de las causas, las posibilidades de haber prevenido el hecho y la atribución de responsabilidades (personales, institucionales, políticas, sociales, etc.). En ocasiones, y siguiendo con la lógica de Martín Baró (1990), la culpabilizacion a las víctimas o sus familiares se convierte en instrumento de control social que actúa como justificador de la violencia y la impunidad al tiempo que distorsiona las responsabilidades reales (Beristain, Dona, Páez, Pérez Sales \& Fernández, 1999). El 'algo habrá hecho', se convirtió en la justificación por excelencia de las desapariciones en Argentina, calando en el discurso cotidiano de amplias capas de la sociedad (Lira, 1991) y aislando a las víctimas y sus familiares.

Los traumas colectivos rompen los lazos de relación entre el individuo y la comunidad generando sensación de exclusión y soledad existencial (Blanco, Díaz \& García del Soto, 2006). Además alteran las creencias en la bondad de la gente y la confianza en ella, así como hacen disminuir el valor que nos otorgamos en la contribución social -la sensación de que lo que hacemos es valorado por la comunidad-y por ende, de nuestra motivación y dignidad. Finalmente, provocan la sensación de no saber hacia dónde va el mundo, se es incapaz de entenderlo, predecirlo y controlarlo (Pérez Sales, Eiroá, Olivos, Barbero, Fernández Liria \& Vergara, 2012; Corsini, 2004; Janoff-Bulman, 1989).

Pese a todo, diversas experiencias indican que las víctimas y los sobrevivientes han desarrollado estrategias de afrontamiento marcadas por la movilización y/o el compromiso político. La lucha contra el olvido y la conmemoración testimonial transforma el sufrimiento individual en testimonio social y en un arma política, parece servir para disminuir la sintomatología (Becker \& Lira, 1989).

Esta investigación busca identificar las consecuencias psicosociales de la represión política ejecutada durante la última dictadura militar. En concreto queremos conocer el impacto en términos de estrés postraumático, duelo, búsquela de sentido e impacto en el sistema de creencias, así como las estrategias de afrontamiento utilizadas para enfrentar el suceso traumático y el apoyo social obtenido para ello.

\section{Método}

\section{Muestra}

La muestra $(\mathrm{N}=52)$ incluye a personas ex detenidas $(\mathrm{n}=22)$ y familiares de personas detenidas desaparecidas (madres, padres, hermanos/as, hijos/as o esposas/viudas) $(\mathrm{n}=30)$. El colectivo de familiares está compuesto predominantemente por mujeres, mientras que la distribución es más equitativa entre la población ex detenida.

\section{Técnicas de investigación e instrumento}

El uso tan solo de cuestionarios puede resultar agresiva para la gente, quienes pueden tener la percepción de que estos no recogen la totalidad de su experiencia. Para enfrentar estos obstáculos, las entrevistas se convirtieron en un buen método para promover la confianza y comprender los discursos de la población (Arnoso \& Eiroá, 2010). Una vez construido el vínculo con la gente se procedió a entregar un cuestionario que permitiese cuantificar algunas de las cuestiones.

El cuestionario incluyó las siguientes variables: Trastorno de estrés post-traumático (Brewin et al., 
2002) en los meses inmediatamente posteriores al evento traumático $(\alpha 0.78)$ y en la actualidad ( $\alpha$ $0.76)$, usando como criterio la existencia de al menos seis (6) síntomas de la escala. Una subescala de doce (12) ítems del Inventario de duelo revisado de Texas (García, Landa, Trigueros \& Gaminde, 2001), con un formato de respuesta donde $1=$ totalmente verdadero y $5=$ totalmente falso $(\alpha$ 0.86) $(12=$ nada alterado y $60=$ totalmente alterado). Búsqueda de sentido: dos (2) ítems de la escala VIVO (Pérez Sales et al., 2012) con formato de respuesta dicotómico Sí/No. Apoyo Social: ocho (8) ítems (Pérez Sales, Bacic \& Duran, 1998; Pérez Sales et al., 2012) con formato de respuesta dicotómico Sí/No.

Se realizó un análisis factorial que arrojó dos factores: el primero, que agrupó los ítems de falta de apoyo (28.89\% de la varianza explicada; $\alpha 0.71)$ y un segundo factor que recogía los ítems positivos de apoyo (21.73\% de varianza explicada; $\alpha 0.55)$. Impacto en las creencias básicas: seis (6) ítems de la escala de creencias básicas de Corsini (2004) ( $1=$ totalmente falso y $5=$ totalmente verdadero). El análisis factorial agrupó los ítems en un solo factor que explicaba el $59.85 \%$ de la varianza ( $\alpha$ 0.85). Estrategias de afrontamiento: una escala ad hoc de ocho (8) ítems a partir de la revisión de las propuestas de Lazarus y Folkman (1986) y Pérez Sales y colaboradores (2012) con un formato de respuesta dicotómico (Sí/No). El análisis factorial con rotación varimax produjo dos factores: el primero agrupaba aquellos ítems que hacían mención a un tipo de afrontamiento activo (31.99\% de la varianza explicada; $\alpha 0.67)$; el segundo, que agrupaba aquellos ítems que caracterizaban un tipo de afrontamiento de evitación y el retraimiento (20.79\% de varianza explicada; $\alpha 0.66)$. Identidad asociada al trauma: siete (7) ítems de la escala VIVO (Pérez Sales et al., 2012) con un formato de respuesta dicotómico acuerdo/desacuerdo que convergen en un solo factor ( $40 \%$ v.e.).

Con el sumatorio de los ítems se construyó una variable continua donde $0=$ anclaje en identidad de víctima y $7=$ identidad de sobreviviente y protagonista de la experiencia ( $\alpha$ 0.71). Las variables sociodemográficas que se recogieron fueron: sexo, edad, ideología política y nivel de exposición a la violencia (familiar de detenido/a desaparecido/a o ex detenido/a político/a).

Se realizaron análisis descriptivos, factoriales y correlacionales utilizando el programa estadístico Statistical Package for the Social Sciences. Se analizan las diferencias en función del nivel de exposición a la violencia. Los datos cualitativos fueron analizados a través del programa Atlas T. Se recurrió a un análisis de contenido entre 3 jueces ciegos e independientes que confirmaron un sistema de categorías altamente fiable.

\section{Resultados}

\section{Sintomatología postraumática}

La mayoría no padeció ni padece hoy estrés postraumático aunque persistan algunos síntomas en la actualidad. Se describen episodios que reflejan síntomas aislados, como irritabilidad, reacciones de híper vigilancia o pesadillas derivadas de la experiencia de internamiento y la adaptación a la 'institución total'. Estas reacciones, aunque eran más habituales en el pasado, suelen reaparecer ante episodios que hacen mención a los hechos (conmemoraciones, exhumaciones, visitas a lugares de la memoria, aniversarios, etc.).

Estás a la que salta, que nadie te despierte así de golpe [...] por todo eso que produjo, cuando nos sacaban a torturar por la noche y te despertaban a la madrugada a los golpes, entonces cualquier cosa te hace saltar así, como si fuese a ocurrir lo mismo. (David, ex detenido) Cuando hablo mucho de esto que pasó, luego ando como loco varios días, me altero muchísimo y necesito descargue. Duermo y estoy con las imágenes ahí, salgo y estoy con esas imágenes. (Ernesto, ex detenido)

\section{Búsqueda de sentido}

La mayoría de la población afectada sabe por qué pasó, asumen su protagonismo en las actividades militantes y consideran que es preciso rescatar los motivos de las luchas y de las desapariciones. Aunque la mayoría pudiese dar sentido a su experiencia, solo la mitad afirmaron que entender por qué suce- 
TABLA 1.

TEPT, búsqueda de sentido, duelo, alteración en las creencias y apoyo social percibido

\begin{tabular}{|c|c|c|c|c|c|}
\hline & & $\begin{array}{l}\text { Familiar } \\
(\mathrm{n}=30)\end{array}$ & $\begin{array}{c}\text { Ex -detenida } \\
\quad(\mathrm{n}=22)\end{array}$ & Sig. & Total \\
\hline \multirow{2}{*}{ TEPT } & Antes & $M=6.2$ & $M=5.3$ & 1.23 & $M=5.82$ \\
\hline & Ahora & $M=2.5$ & $M=2.9$ & 0.295 & 2.69 \\
\hline \multirow{2}{*}{ Búsqueda de sentido } & Me tranquiliza entender por qué sucedieron las cosas & $46.7 \%$ & $68.2 \%$ & 2.38 & $55.8 \%$ \\
\hline & ¿Por qué me pasó a mí? El azar es injusto & $43.3 \%$ & $13.6 \%$ & $5.25^{*}$ & \\
\hline Duelo & Duelo & $M=47.50$ & $M=43.04$ & 2.57 & $M=45.61$ \\
\hline \multirow{7}{*}{ Creencias básicas } & Visión del yo digno de respeto & $M=2.83$ & 1.90 & $4.59^{*}$ & $M=2.32$ \\
\hline & Visión del mundo social benevolente & $M=3.33$ & 2.59 & 2.82 & 3.03 \\
\hline & Visión del mundo benevolente & $M=2.17$ & $M=1.41$ & $4.7^{*}$ & $M=1.72$ \\
\hline & Sentido del mundo & $M=2.27$ & $M=1.27$ & $6.54^{*}$ & $M=1.62$ \\
\hline & Integración social & $M=3.13$ & $M=2.18$ & $5.09 *$ & $M=2.46$ \\
\hline & Motivación y eficacia & $M=2.57$ & $M=1.82$ & 2.94 & $M=2.08$ \\
\hline & Impacto total en el sistema de creencias & $M=16.30$ & $M=11.18$ & $8.14 * *$ & $M=13.74$ \\
\hline \multirow{10}{*}{ Apoyo social } & Sentí que la sociedad nos culpaba & $50 \%$ & $45.5 \%$ & 0.10 & $48.1 \%$ \\
\hline & La sociedad nos dio la espalda & $76.7 \%$ & $45.5 \%$ & $5.33^{*}$ & $63.5 \%$ \\
\hline & Me parecía que la gente nos humillaba & $23.3 \%$ & $9.1 \%$ & 1.79 & $17.3 \%$ \\
\hline & Las amistades nos dieron la espalda & $36.7 \%$ & $22.7 \%$ & 1.15 & $30.8 \%$ \\
\hline & Media apoyo social negativo & 1.87 & 1.23 & 2.90 & 1.55 \\
\hline & $\begin{array}{l}\text { Nunca me he sentido sola, siempre hay gente que me } \\
\text { ha acompañado }\end{array}$ & $40 \%$ & $18.2 \%$ & 2.83 & $30.8 \%$ \\
\hline & Me di cuenta de que la gente nos quería y respetaba & $36.7 \%$ & $40.9 \%$ & 0.097 & $38.5 \%$ \\
\hline & Mi familia estuvo conmigo & $66.7 \%$ & $86.4 \%$ & 2.62 & $75 \%$ \\
\hline & Me apoyé en quienes habían pasado cosas parecidas & $60 \%$ & $59.1 \%$ & 0.004 & $59.6 \%$ \\
\hline & Media apoyo social positivo & 2.03 & 2.04 & 8.83 & 2.03 \\
\hline
\end{tabular}

Fuente: elaboración propia

dieron las cosas les tranquilizaba. Una minoría creía que su experiencia había dependido del azar, no encuentran sentido a lo ocurrido y se esfuerzan por negar la actividad social y/o política. Esto ocurre de forma significativa entre los familiares de personas detenidas desaparecidas.

A mi papá se lo llevaron porque era un militante del campo popular que luchaba por los derechos de los demás y era muy buen compañero. (Nora, hija de detenido desaparecido)

Yo me niego a decir que no sé por qué ocurrió [...] andábamos en buscar un Jujuy distinto; eso es lo que debemos rescatar [...] los motivos por los que desaparecieron a tantos compañeros. (Gastón, ex detenido)

Mi hermano era muy bueno, no se metía con nadie, era un estudiante ejemplar, no merecía lo que le pasó. (Nadia, hermana de detenido desaparecido)
Yo creo que a mí me detienen por confusión, [...] porque no puedo entender [...]. Directamente no me interesaba la política, solo alguna reunión de grupos, pero lo normal. (Rosario, ex detenida)

A menudo las personas ex detenidas tuvieron la sensación de tener que excusarse ante los familiares por haber sobrevivido a la represión mientras otros no lo hicieron. Así se atribuyen causales ancladas al azar o a la arbitrariedad de los militares para enfrentar la inducción a la culpa y la responsabilización por lo ocurrido.

A veces hemos sentido cómo nos culpaban, por qué no está mi mamá o mi papá y vos estás acá y ha habido que explicar que no teníamos la culpa, que la vida no dependía de nosotros, que no era que los mataron a los otros para que yo quedara vivo, que no es que han cambiado la vida de un compañero por la mía, que nuestras 
TABLA 2.

Afrontamiento e identidad de sobreviviente

\begin{tabular}{|c|c|c|c|c|c|}
\hline \multirow{10}{*}{ 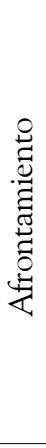 } & & Familiar & Ex -detenida & Sig. & Total \\
\hline & Me organicé con otros familiares & $66.7 \%$ & $54.5 \%$ & 0.78 & $61.5 \%$ \\
\hline & Traté de buscar información & $56.7 \%$ & $59.1 \%$ & 0.031 & $57.7 \%$ \\
\hline & Reforcé mi lucha política & 40 & $63.6 \%$ & 2.83 & $50 \%$ \\
\hline & Media afrontamiento activo & 2.30 & 2.72 & 1.25 & 2.51 \\
\hline & Preferí callar y llevar la pena por dentro & $30 \%$ & $27.3 \%$ & 0.046 & $28.8 \%$ \\
\hline & Trataba de distraerme en actividades para evitar pensar & $26.7 \%$ & $31.8 \%$ & 0.16 & $28.8 \%$ \\
\hline & Me callé para evitar que nos pasara algo & $23.2 \%$ & $22.7 \%$ & 0.003 & $23.1 \%$ \\
\hline & Me resigné porque dejé de creer en la justicia & $16.7 \%$ & $9.1 \%$ & 0.62 & $13.5 \%$ \\
\hline & Media afrontamiento evitación & .096 & 0.90 & 0.029 & .93 \\
\hline \multirow{8}{*}{ 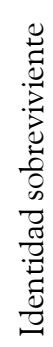 } & Creo que me he quebrado con lo que pasó & $46.7 \%$ & $9.1 \%$ & $8.41 * *$ & $30.8 \%$ \\
\hline & Todo sufrimiento es una oportunidad de superación & $60 \%$ & $72.7 \%$ & 0.90 & $65.4 \%$ \\
\hline & Ser testigo da sentido a la vida & $75.9 \%$ & $100 \%$ & $5.89 * *$ & $86 \%$ \\
\hline & Me siento muy cerca de quienes han pasado lo mismo que yo & $70 \%$ & $90.9 \%$ & 3.32 & $78.8 \%$ \\
\hline & Me vi fuerte, resistiendo & $71.4 \%$ & $90.9 \%$ & 2.92 & $80 \%$ \\
\hline & Hay experiencias que me han hecho más fuerte & $83.3 \%$ & $95.5 \%$ & 1.82 & $88.5 \%$ \\
\hline & Me quedó una profunda sensación de dignidad & $82.8 \%$ & $90.9 \%$ & 0.70 & $86.3 \%$ \\
\hline & Media identidad sobreviviente & 4.96 & 6.28 & $8.25 * *$ & 5.62 \\
\hline
\end{tabular}

Fuente: elaboración propia

vidas estuvieron en manos de gentes que hizo lo que se les dio la gana. (Alfonso, ex detenido)

\section{Apoyo social percibido}

La mayoría de las personas afectadas sintieron que la sociedad les dio la espalda, casi la mitad se sintió culpabilizada por la sociedad, un tercio percibió que incluso sus amistades los dejaron solo y casi una quinta parte expresó momentos de humillación por su condición. A la inversa, más de un tercio reconoció que la gente la quería y respetaba. Aunque la mayoría encontró apoyo en personas que habían pasado situaciones parecidas y también en el espacio familiar, menos de la mitad expresó no haberse sentido nunca sola. Es decir, aun habiendo encontrado espacios de apoyo, la mayoría sintió muchos momentos de soledad vinculados a su experiencia represiva.

El apoyo de la sociedad ha sido malísimo acá, como que tenías una peste encima. [.. .] con los otros ex [. . .] pasó tiempo hasta que volvimos a estar juntos. La libertad al principio es rara, es incertidumbre, es soledad. (Camilo, ex detenido)
La alteración en el proceso de duelo

Aún hoy el proceso de duelo se encuentra alterado, tanto entre los familiares como entre los ex detenidos políticos. A pesar de que el paso del tiempo y la investigación acerca del pasado han permitido confirmar los asesinatos, la ausencia del cuerpo y la persistencia de la incertidumbre dificultan este proceso. Las personas ex detenidas refieren que además del duelo por la pérdida de seres queridos, interpretan la dictadura y la cárcel como la desaparición de un proyecto político, de compañeros/as de militancia y de una generación comprometida con un futuro distinto.

No hemos hecho ni ningún duelo, [...] vivimos en la incertidumbre [...], porque vos icuándo te convencés de una muerte?, cuando ves aunque sea el cajón, pero así... (Mónica, esposa de detenido desaparecido) No solo es el duelo familiar, [...] también eran nuestros compañeros [...] y eran personas tan brillantes, tan lúcidas, es una pérdida comunitaria también, la generación que se han llevado, el proyecto político que 
teníamos, [...], soñábamos con un país distinto, y eso se han llevado [...] (Rodrigo, ex detenido)

\section{El impacto en el sistema de creencias}

En general, el sistema de creencias básicas se ha podido reconstruir, aunque los familiares han tenido más dificultades para ello que la población ex detenida, sobre todo en lo relativo a la visión del yo digno y de respeto, la pérdida de confianza en la vida o el impacto en la visión del mundo benevolente. Además y en mayor medida, la población ex detenida se sintió más distante de la gente y que que la vida había dejado de tener sentido . En los testimonios hicieron referencia a estas cuestiones, tanto en términos negativos como de reconstrucción y fortalecimiento. Es el caso de las creencias religiosas, icómo comprender que, en caso de existir un ser supremo, hubiese podido tolerar tanta barbarie? O a la inversa, icómo comprender haber sobrevivido sin la ayuda de Dios?

Perdí tres hijos, una nieta. Mi hija y yo nos pasamos casi siete años encerradas, torturas, de todo pasamos nosotras, [...] mi vida ha sido muy dolorosa. ¿Cómo voy a creer en Dios? Antes sí, pero iahora? [...]tanto sufrimiento y ino hizo nada? (Esther, ex detenida y madre de detenidos desaparecidos)

Por qué no nos tocó, [... yo a veces no me explico cómo me salvé de tantas, cómo que pude volver a nacer muchas veces, a veces digo que ya estoy de prestado acá, después de tantos peligros que hemos pasado [...] así que de alguna manera creo que Dios me debió ayudar. (Gastón, ex detenido)

Como se mencionó anteriormente, muchos testimonios afirman que la vida dejó de tener sentido e incluso algunos familiares se quitaron la vida como consecuencia de los hechos. Sin embargo, en general las personas encontraron nuevas motivaciones para vivir.

Mi mamá sufrió mucho cuando desaparecieron a mi papá. [...] Nos crió a las dos, hasta que nos hicimos grandes [...]. Después se suicidó. Creo que la vida dejó de tener sentido para ella después de la desaparición del papá. (Sonia, hija de detenido desaparecido)

Cuando asesinaron a mi hija Alejandra [...] todo se hizo oscuro, el mundo era muy gris [...]. Pero Mónica [...]i Ay, cuando recuperamos a mi nieta! Ahí sí vi la luz nuevamente, otra vez la vida volvió a tener sentido. (Norma, madre de asesinada política)

\section{Estrategias de afrontamiento}

Las estrategias más citadas por los sujetos se relacionan con la movilización social, en concreto: la organización con otras personas afectadas, la búsqueda de información acerca de lo que había pasado y el fortalecimiento de la lucha política acompañado del orgullo hacia lo que hicieron sus familiares o compañeros/as de militancia. Cerca de un tercio de las personas entrevistadas indicaron haberse callado y preferido llevar la pena por dentro o haber hecho esfuerzos para distraerse con otras actividades y así evitar recordar lo que les había ocurrido. Un cuarto de la población sostuvo haberse callado en algún momento para evitar que les pasase algo y una minoría indicó haberse resignado por haber dejado de creer en la justicia. Las estrategias que la población entrevistada utilizó para enfrentar la situación traumática fueron similares atendiendo al nivel de exposición a la violencia. En el caso de las personas ex detenidas, entre las múltiples estrategias descritas, la claridad y conciencia política son las estrategias más reconocidas para hacer frente al horror, incluso habiéndose visto fortalecidas como consecuencia de la experiencia. "Si no estás consolidado ideológicamente, por más fuerte que seas, largás [...]" (Darío, ex detenido).

Cuando entré a la cárcel no sabía que yo era un preso político, me di cuenta ahí adentro, con las discusiones, porque me fui haciendo, yo creía que lo que había hecho era solo defender a algunos trabajadores. (Camilo, ex detenido)

El afrontamiento activo de los familiares se caracterizó inicialmente sobre todo, por la búsqueda de información en las comisarías y centros penitenciarios, y en la actualidad, por la organización en torno a organizaciones de víctimas y de derechos 
humanos para reclamar memoria, verdad y justicia. Nuclearse en torno a los organismos ha posibilitado mantener viva la memoria y promover el juicio y castigo a los responsables, así como encontrar espacios de ventilación y sostenimiento emocional.

Mi mama salía a buscar noticias de mi hermano, a ver dónde estaba, le decían que andaba en tal lugar y allí te pueden dar una noticia, y mientras ella andaba todo el día, porque ella salía de mi casa a las siete de la mañana a San Salvador y volvía a las 12 de la noche. (Felisa, hermana de detenidos desaparecidos)

La contención que mis compañeras han representado para mí, en un camino que me encontraba sola. Poder encontrar un espacio en la asociación y dar mi testimonio me ayudó a recuperar mi identidad de luchadora social y a sentirme más cerca de mis pares. (Lucrecia, ex detenida)

\section{Identidad sobreviviente}

La población entrevistada desarrolló una identidad de sobreviviente versus víctima, de forma significati- va entre los/as ex detenidos/as. A pesar de los abusos soportados, se sostiene que todo sufrimiento es una oportunidad de superación. Ellos se vieron fuertes y resistieron la situación, afirman que la experiencia les fortaleció y que al final les quedó una profunda sensación de dignidad. Además, de forma global se desarrolló una identidad de pertenencia y cercanía con las personas que habían pasado por lo mismo. También es evidente que en general, consideran que ser testigos de la experiencia le da sentido a sus vidas, especialmente entre la población ex-detenida y no tanto en los familiares. Solo un tercio de la población entrevistada sintió haberse quebrado con lo que ocurrió (especialmente los familiares).

Yo siento que me marcó, que tengo que ser un luchador permanente, yo abracé ese compromiso, es la vida que me tocó, la utopía que elegí, [...] es lo que me toca por mis compañeros. (Darío, ex detenido)

Estos hijos de puta no se van a pensar encima que nos quebraron, no, yo no quiero ser una víctima, no quiero que disfruten del dolor que han causado [...]; al revés,

TABla 3.

Correlaciones de las variables de afectación psicosocial

\begin{tabular}{|c|c|c|c|c|c|c|c|c|c|c|}
\hline & 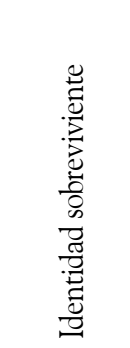 & 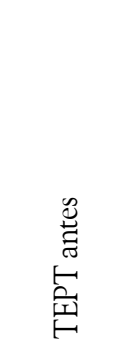 & 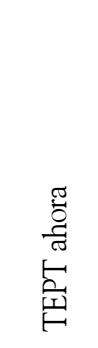 & 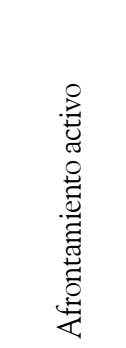 & 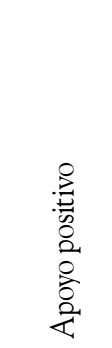 & 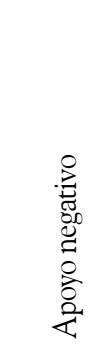 & 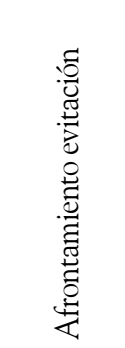 & $\frac{\stackrel{\varrho}{\Xi}}{\stackrel{\Xi}{\Xi}}$ & 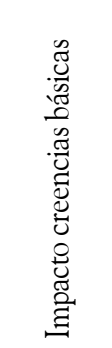 & 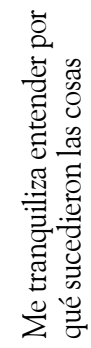 \\
\hline Identidad sobreviviente & 1 & & & & & & & & & \\
\hline TEPT antes & -0.250 & 1 & & & & & & & & \\
\hline TEPT ahora & -0.080 & $0.334^{*}$ & 1 & & & & & & & \\
\hline Afrontamiento activo & $0.577 * *$ & .0015 & -0.173 & 1 & & & & & & \\
\hline Apoyo positivo & $0.489 * *$ & -0.223 & -0.208 & $0.605 * *$ & 1 & & & & & \\
\hline Apoyo negativo & 0.081 & 0.209 & 0.064 & 0.149 & 0.114 & 1 & & & & \\
\hline Afrontamiento evitación & -0.222 & $0.281^{*}$ & 0.119 & -0.223 & -0.158 & $0.383 * *$ & 1 & & & \\
\hline Duelo & -0.089 & $0.352 *$ & 0.171 & -0.003 & -0.013 & 0.183 & 0.008 & 1 & & \\
\hline Impacto creencias básicas & $-0.448^{* *}$ & $0.464 * *$ & 0.144 & $-0.363 * *$ & $-0.345^{*}$ & $0.375 * *$ & $0.506^{* * *}$ & $0.282 *$ & 1 & \\
\hline $\begin{array}{l}\text { Me tranquiliza entender por qué } \\
\text { sucedieron las cosas }\end{array}$ & $0.404 * *$ & -0.125 & 0.079 & $0.288^{*}$ & 0.186 & 0.250 & -0.109 & -0.050 & -0.206 & -1 \\
\hline
\end{tabular}

Fuente: elaboración propia 
todo mi objetivo es luchar para que estos hijos de puta vayan presos. (Bartolina, hija de asesinado político) Me marcó la vida, definitivamente sí [...]. Yo tenía una cuestión así de quedarme en ser víctima [...] crecícon el discurso de mi mamá: nosotras somos víctimas. Y eso, a mí sí me trajo consecuencias [...] el no poder salirse del lugar de víctima. Si una es víctima se sufre todo el tiempo, era una persona sufriente por todo [...]. Correrme de ese lugar me ha costado mucho. En realidad yo me siento mejor ahora que me siento que soy protagonista de mi vida. (Elisa, hija de detenido desaparecido)

\section{De la afectación al crecimiento}

psicosocial: variables asociadas

En el análisis se encontraron correlaciones entre la existencia de TEPT en el pasado, las formas de afrontamiento marcadas por la evitación, una mayor alteración en el proceso de duelo y el impacto negativo en las creencias básicas. Asimismo se encontraron relaciones positivas entre un afrontamiento activo, un mayor apoyo social positivo, la posibilidad de dar sentido a lo ocurrido y la generación de una identidad de sobreviviente.

\section{Discusión y conclusiones}

Los resultados de este trabajo muestran que la mayoría de la población no desarrolló una patología postraumática severa, aunque algunos de estos síntomas pudieran emerger nuevamente ante acontecimientos que activan el pasado traumático. Un estilo de afrontamiento de evitación se asociaría a una mayor sintomatología postraumática y a mayores dificultades en los procesos de elaboración del duelo, dificultado este por la inexistencia de los restos para constatar la muerte y la ausencia elementos simbólicos como rituales (Kordon et al., 1995; Lira, 1991). Además del duelo tradicional, se encontró un duelo de carácter político capaz de integrar las múltiples pérdidas que suele acarrear la violencia política (Becker et al., 1990). Por su parte, las estrategias de afrontamiento caracterizadas por la evitación se asociaron a la sensación de no comprender los motivos por los que habían sido afectados por la represión, así como a un mayor malestar psicológico medido en términos de estrés postraumático. Es decir que aquellas personas con menos claridad política sobre sus actos o sobre las actividades que desarrollaban sus familiares detenidos/as desaparecidos/as, refirieron mayor malestar psicológico asociado a la imposibilidad de encontrar un sentido a los hechos.

El resistirse a aceptar lo ocurrido, la negación, ocultar los sentimientos y aislarse del entorno, han sido definidas como conductas desadaptativas a largo plazo por la literatura previa. Los meta-análisis de Compas, Connor-Smith, Saltzman, Thomsen y Wadsworth (2001) confirmaron que la falta de compromiso o abandono conductual, la evitación cognitiva y conductual, se asociaban a mayor ansiedad y depresión, menor ajuste social y a la enfermedad. Un estudio realizado en Irlanda del Norte en la época de la violencia colectiva confirmó que el afrontamiento de evitación era el que se asociaba más fuertemente al malestar (Brown, Mulhem \& Joseph, 2002).

Igualmente, se encontró que la falta de apoyo social se asocia con una mayor alteración en el sistema de creencias y con selccionar más estrategias de evitación para enfrentar la experiencia traumática, de forma coherente con lo señalado en estudios previos. La investigación de Zapata-Sepúlveda, López-Sánchez y Sánchez-Gómez (2009), cuyo objetivo principal era estudiar los efectos psicológicos de experiencias de prisión y tortura política en la concepción de mundo de un grupo de chilenos supervivientes, encontró que la concepción negativa del mundo se relacionaba con la interpretación de que se vive en un mundo influenciado por el ex régimen militar chileno y con la insatisfacción respecto a la sociedad chilena, debido a que perciben un apoyo de su parte al mismo régimen político.

Congruentemente, aunque algunos estudios han encontrado que las personas torturadas o víctimas directas refieren una peor imagen de sí mismas en comparación con los familiares de las víctimas (Magwaza, 1999), en el presente estudio se encontró que la visión del yo digno y de respeto era significativamente más negativa entre los familiares de personas detenidas desaparecidas que entre la población ex detenida. Este hallazgo podría tener relación con 
el hecho de que los familiares de las víctimas tuvieron más dificultades para dar sentido a los hechos, haciendo más atribuciones de sentido al azar que a las explicaciones sociopolíticas esgrimidas por la población ex detenida, la cual afirmaba que la claridad y el afrontamiento político habían sido los elementos principales para mantenerse fuertes y no quebrarse en las cárceles y/o sesiones de tortura. Estos datos son coherentes con el estudio de Basoglu y colaboradores (1996), quienes encontraron una menor sintomatología y prevalencia de TEPT en activistas políticos turco torturados (18\%) que en presos no políticos torturados (39\%), planteando así que las personas con creencias estructuradas y mayor compromiso político enfrentan mejor el estrés de la violencia colectiva.

Por otro lado, aunque estudios previos han insistido en los efectos a largo plazo del impacto negativo de la violencia en el sistema de creencias básicas (Cabrera, 2006; Corsini, 2004; Janoff-Bulman, 1989), la alteración en la muestra analizada fue moderada. En ella prevalece la afectación de aquellas relacionadas con la confianza en los otros, mientras que el resto de las dimensiones se restablecieron con el paso de los años. Es decir, aunque la violencia genera un impacto en las creencias básicas, los resultados de este estudio apuntan a que experiencias vitales positivas pueden colaborar en su restablecimiento, lo cual sugiere que esta alteración no es necesariamente definitiva (Arnoso \& Eiroá, 2010).

En definitiva, la violencia destructiva y deshumanizada y el esfuerzo por acabar con la resistencia fueron relativamente fallidos: la supervivencia y la organización prevalecieron sobre la muerte pretendida y este tipo de afrontamiento se asoció a un mejor bienestar psicosocial (Becker \& Lira, 1989). La implicación en actividades colectivas, ya sea de ayuda o de participación en la comunidad, es una forma de actividad grupal que ayuda a formular y encontrarle sentido a los hechos traumáticos, colaborando con la recuperación de la pérdida colectiva (Lifton, 1980).

\section{Referencias}

Arnoso, M., \& Eiroá, F. (2010). Psychosocial research and action with survivors of political violence in
Latin America: methodological considerations and implications for practice. Intervention 8(1), 3-13.

Basoglu, M., Paker, M., Özmen E., Tasdemir Ö., Sahin D., Ceyhanli A., ... Sarimurat, N. (1996). Appraisal of self, social environment, and State authority as a possible mediator of post-traumatic stress disorder in tortured political activists. Journal of Abnormal Psychology, 105, 232-236.

Becker, D., \& Lira, E. (1989). Derechos Humanos: Todo es según el dolor con que se mira. Santiago de Chile: ILAS.

Becker, D., Castillo, M., Gómez, E., Salamovich, S., Weinstein, E., Dominguez, R., ... \& Rojas, E. (1990). Muerte y duelo: Los familiares de ejecutados y su psicoterapia. Psicología social de la guerra: Trauma y terapia. El Salvador: UCA.

Beristain, C., Dona, G., Páez, D., Pérez -Sales, P., \& Fernández, I. (1999). Reconstruir el tejido social. Un enfoque crítico de la ayuda humanitaria. Barcelona: Icaria Antrazyt.

Blanco, A., Díaz, D., \& García del Soto, A. (2006). Recovering the context in posttraumatic stress disorder: The psychosocial trauma in victims of political violence and terrorism. Estudios de Psicología, 27, 333-350.

Brewin, C. R, Rose, S., Andrews, B., Green, J., Tata, P., McEvedy, C., ... Foa, E. B. (2002). Brief screening instrument for post-traumatic stress disorder. The British Journal of Psychiatry, 181, 158-62.

Brown, J., Mulhem, G., \& Joseph, S. (2002). Incident related stressors, locus of control, doping and psychological distress among fire-fighters in Northern Ireland. Journal of Trauma and Stress, 15(2), 161-168.

Cabrera, M. L. (2006). Violencia e impunidad en comunidades mayas de Guatemala. La masacre de Xaman desde una perspectiva psicosocial. Guatemala: ECAP.

Compas, B. E., Connor-Smith, J. K., Saltzman, H., Thomsen, A. H., \& Wadsworth, M. E. (2001). Coping with stress during childhood and adolescence: Problems, progress and potential in theory and research. Psychological Bulletin, 127(1), 87-127.

Corsini, S. (2004). Everyday Emotional Events and Basic Beliefs. Tesis de doctorado no publicada. University of Louvain. Louvain la Neuve. 
Fernández-Liria, \& Rodríguez Vega (2002). Habilidades de entrevista para psicoterapeutas. Bilbao: Desclée de Brouwer.

García, J. A., Landa, P., Trigueros, M., \& Gaminde, I. (2001). Inventario de experiencias en duelo: adaptación al castellano, fiabilidad y validez. Atención Primaria, 27,

Janoff-Bulman, R. (1989). Assumptive worlds and the stress of traumatic events: Applications of the schema construct. Social Cognition, Special Issue: Social Cognition and Stress, 7, 113-136.

Kordon, D., Edelman, L., Lagos D., \& Kersner, D. (1995). La Impunidad: una perspectiva psicosocial y clínica. Buenos Aires: Sudamericana.

Lazarus, R. S., \& Folkman, S. (1986). Estrés y procesos cognitivos. Barcelona: Ediciones Martínez Roca.

Lifton, R. J. (1980). The concept of the survivor. En J. E. Dimsdale (Ed.). Survivors, victims, and perpetrators: Essays on the Nazi holocaust (pp.). Washington, DC: Hemisphere.

Lira, E. (1991). Psicología de la amenaza política y el miedo. Santiago de Chile: Chileamerica. CESOC.

Magwaza, A. S. (1999). Assumptive world of traumatized south african adults. The Journal of Social Psychology, 139, 622-630.
Martín Baró, I. (1990). De la guerra sucia a la guerra psicológica: el caso de El Salvador. El impacto psicosocial de la guerra. En I. Martín Baró (Coord.). Psicología social de la guerra (pp.). El Salvador: UCA.

Pérez Sales, P., Eiroá, F., Olivos, P., Barbero, E., Ferández-Liria, A., \& Vergara, M. (2012). VIVO Questionnaire. A measure of human worldviews and identity in trauma, crisis and loss. Validation and preliminary findings. Journal of Loss and Trauma (en prensa).

Pérez-Sales, P. Bacic, R., \& Durán, T. (1998). Muerte y desaparición forzada en la Araucanía. Una aproximación étnica. Chile: Universidad Católica de Temuco.

Summerfield, D. (1999). A critique of seven assumptions behind psychological trauma programmes in war-affected areas. Social Science and Medicine, 48, 1449-1462.

Zapata-Sepúlveda, P. López-Sánchez, F., \& SánchezGómez, M. (2009). Concepción de mundo, aspectos contextuales y bienestar psicológico en chilenos supervivientes a experiencias de prisión y tortura por motivos políticos a más de 30 años de ocurridos los hechos. Universitas Psychologica, 8(3), 761-769. 